\title{
Introducing Change of Early Implementation of Learning Spanish as a Foreign Language in the Texas Education System
}

\author{
Krystin White ${ }^{1 *}$
}

\begin{abstract}
It has been shown that humans have the most capacity to learn language at an early age, so why does the American education system wait until high school and higher education to put emphasis on learning a foreign language? While the initial purpose of my research question was to investigate why the American education system lacks national requirements, my research investigates why the Texas education system does not have state wide requirements in place for foreign language learning, especially Spanish, during early education. I conducted my research by getting the opinions of various Texas educators on this topic. The responses to my questionnaire revealed that the educators agree that funding, limited number of educators, lack of resources, and opinions against learning Spanish as a foreign language at a young age are potential factors that hinder the implementation of foreign language learning programs at the elementary level. While investigation of the literature and the opinions from the educators provided information about the inefficiency and need for change in the current approach to foreign language learning in the Texas education system, more research is needed before making changes in the Texas and American education system.
\end{abstract}

\section{Keywords}

Foreign Language Learning - Texas - Education Requirements

${ }^{1}$ Department of Audiology and Speech Language Pathology, University of North Texas

*Faculty Mentor: Dr. Jongsoo Lee

\section{Contents}

\section{Introduction}

1 Age and Foreign Language Acquisition

1.1 Language Learning in America . . . . . . . . . 2

1.2 Language Learning in Other Countries ...... . 2

1.3 Opinions Against Early Language Learning . . . . 3

1.4 Different Approaches to Foreign Language Learning 3

2 Methodology

3 Results

3.1 Open-Ended Questions . . . . . . . . . . . . . . 5

3.2 Likert Scaled Questions . . . . . . . . . . 8

4 Limitations

Directions for Future Research

6 Discussion

10

7 Conclusion

Author Biography

References

\section{Introduction}

1 Many researchers show that the human brain has the greatest 2 ability to learn, especially language, during youth than at any other period in the human lifespan. While other countries are capitalizing on the plasticity of the brain of a young learner, America is failing to do so by not having national educational requirements for foreign language learning in early education. Unlike its European counterparts, America waits until high school and higher education to put emphasis on learning a foreign language. Some researchers would argue that by that point in a person's life the likelihood of achieving proficiency in a foreign language is not favorable.

Why does the American education system not have national language requirements in place to utilize the plasticity of the brain at a young age? Some states in America have requirements in place for foreign language learning in elementary education, while other states have no requirements at all. This lack of uniformity in early foreign language requirements shows America's need for national requirements for foreign language learning during early education. 


\section{Age and Foreign Language Acquisition}

It is debated whether there is an optimum age for learning a language and, conversely, an age at which it is impossible to completely learn a foreign language. There is much research targeted to determining if reaching a certain age permits a person from being able to learn a foreign language to the proficiency of a native speaker. Research done by Krashen, Long, and Scarcella shows that those who start foreign language learning as adults do not reach the same proficiency level as those who are exposed to a foreign language during childhood [1]. This study provides evidence that starting foreign language exposure for children at a young age increases their probability to become proficient in the foreign language.

A subsequent study shows the importance and benefits of beginning foreign language learning at an early age. Cardinale shows the necessity of foreign language being taught in schools at an early age [2]. This article articulates that children achieve more proficiency in a foreign language if they begin learning at a young age. The author also presents some of the benefits of foreign language learning which are educational, social, personal implications, and impacts of being exposed to another culture. The findings underscore the additional benefits to a child of mastering a foreign language at an early age.

\subsection{Language Learning in America}

Research conducted by Delvin compared the educational requirements for foreign language learning in Europe and America [3]. The findings show that most European countries have national requirements for learning at least one foreign language in the early education system while the American education does not have any national requirements in place for foreign language learning at any age. This research shows the national requirements for most European countries but only provides a few examples of the individual state requirements in America. Since America does not have national requirements for foreign language learning, it would be beneficial for this study to provide the individual state requirements in some form of visual representation. However, Devlin does show that overall American language requirements are not equivalent to European national standards.

In one article, the need for the United States to have a national foreign language requirement is argued [2]. The argument is made by comparing the difference between educational foreign language requirements in New York school districts and Nevada schools districts. New York schools only require two years of foreign language by the 9th grade and any foreign language taken after that can be used to satisfy the foreign language requirements for New York colleges. Nevada school districts allow children to choose whether they would like to start learning a foreign language at 3rd, 5th, or 8th grade and information for high school foreign language requirements were not available. This examination of the foreign language requirements in two different states shows a significant lack of national standards for foreign language instruction, despite a demonstrated need. The lack of national requirements for foreign language learning in the American education system creates difficulties for implementing foreign language learning for children.

The Texas Education Agency provides the educational requirements for Texas by reporting the Texas Essential Knowledge and Skills (TEKS) for learning languages other than English for elementary age children. ${ }^{1}$ The TEKS currently in place for foreign language learning does not require Texas elementary schools to teach children another language at an early age. The TEKS in place only encourage educators to teach a foreign language. However, if funding is available, educators will begin implementation of foreign language requirements during the 2017-2018 school year. Since legislation for teaching languages other than English is in the early phases of implementation, new questions arise. What factors, other than funding, are hindering the State Board of Education from making the TEKS for elementary school require learning languages other than English? If funding is the only prohibiting factor, why is funding not being made available for educational requirements that have been shown to be very beneficial for young children?

\subsection{Language Learning in Other Countries}

Countries outside the United States are capitalizing on the plasticity and capability of the child's brain to learn a foreign language at a young age. The results reported by Delvin uses the statistics arm of the European Commission from a 2012 report from Eurostat to create a graph, which shows at what age students in various European countries learn second and sometimes third languages [3]. This information provides an example of educational requirements that are effective in foreign language learning for their students early in the education system. This effective model demonstrated by the European education systems could be implemented into the American education system to help the students learn a foreign language at a young age instead of waiting until it is more challenging to become fluent in a language.

There are many other aspects of foreign language learning the United States could implement from other countries [2]. Most other countries start foreign language learning in elementary school while the U.S. usually starts foreign language learning in middle school and high school. By following the example set by other countries, the U.S. could begin foreign language learning at an earlier age. Additionally, the U.S. could emphasize more extensive education of teachers, create appropriate language evaluation tools, and make foreign language become a core subject in the educational curriculum instead of an elective. The American education system would benefit greatly if they followed the examples of foreign language learning set by other countries.

\footnotetext{
${ }^{1}$ Texas Essential Knowledge and Skills. Retrieved 2016 from http://tea.texas.gov/curriculum/teks/.
} 


\subsection{Opinions Against Early Language Learning}

Some research opposes children learning a foreign language at a young age. Farzaneh and Movahed investigate the possibility that second language instruction can hinder first-language acquisition in preschoolers [4]. The main findings are foreign language learning can cause four negative effects on a foreign language learner's first language. The four negative effects they found were language interference, foreign accent, additional effort for the children, and cultural discrepancies. Their findings may not be reliable, however, because no information was provided about the language background of the children and the information was not gathered consistently for all participants. Although the reliability of this study is under question, it shows the possible problems foreign language learning can cause a child if it is done at too early of an age and it also provides insight into the argument against foreign language learning in preschool aged children.

Another argument against foreign language learning is some parents and educators are concerned that starting foreign language learning may place unnecessary stress on the children and interfere with the acquisition and firming of their native language. Billak conducted a 5 year longitudinal study on children from pre-K age to 1 st grade to research this possibility [5]. The children's languages were tested at the end of each school year to observe if any progress in the foreign language or negative effects in the native language had occurred. This study had a large sample size and used a control group of native English speakers to compare to the experimental group of children learning English as a foreign language.

The results from the study showed that while children at the pre-Kinder level and Kinder I did not show overall benefit, the children at the level of Kinder II showed benefit in their foreign language. Overall, the children in Kinder II reached the target goals set for them. Reaching the target goals and increasing proficiency at this level can be explained by the increased concentration on the foreign language and the cumulative effects of the foreign language learning in the earlier grades. In terms of speaking, children in grade 1 scored very high on the test administered at the end of the school year. These scores are further evidence of the cumulative effect of intensive foreign language instruction among children of this age. While the research did show that children do not begin to gain much benefit until they reach the level of Kinder II, the instruction in the earlier levels helped the children reach their proficiency. This research shows the falsehoods in this particular opposition against teaching children a foreign language at a young age [5].

\subsection{Different Approaches to Foreign Language Learn- ing}

Many studies have been conducted to investigate the most efficient and effective way to teach children a foreign language. One study conducted by Bergström, Klatte, Steinbrink, and Lachmann observed the development of first language and foreign language in 2 to 6 year old German kindergarten students who are placed in either an immersion program or a conventional instruction program for foreign language learning [6]. The main findings showed that development of the first language was not affected by the learning of a foreign language and the immersion program was more successful than the conventional instruction program. According to this research, the foreign language learning program of immersion is the better option for children in early education because it allows them to achieve greater proficiency. This research provides insight on what is the best type of educational setting for teaching children a foreign language.

The results from the research performed by Billak show that children's proficiency in their foreign language benefits from the accumulation of foreign language instruction in earlier years [5]. This study also shows that children benefit from intensive foreign language instruction. Children who received instruction heavily based in the foreign language and were reinforced to only speak in the foreign language in the classroom, benefited in terms of proficiency in their foreign language.

Three different methods for teaching children a foreign language were suggested in a study conducted by Shine [7]. The three methods are the structural method, the functional method, and the interactive method. This article strongly suggests the interactive method is the better option for teaching children a foreign language. By breaking the traditional mold of classroom teaching and making the learning creative, interactive, and intriguing, the interactive approach will help increase the proficiency in second language learning.

Another study investigated if overhearing a language during childhood would have an impact on a person's ability to learn and speak that language in adulthood. The study investigated the phonology, morphology, and syntax of approximately 20 college students who were native English speakers and enrolled in their second year of Spanish classes. This research shows exposing children to another language during childhood allows them to have better command of the phonological system for that language and speak with more native-like fluency in adulthood [8]. According to the findings of this research, the American education system could benefit students by exposing them to a foreign language during early education.

Another possible resource for teaching children a foreign language is a new type of bilingual book. Testing was conducted on a bilingual book prototype on Japanese pre-school children. They observed if this would allow the children to naturally learn vocabulary and phrases in English [9]. The main findings of this study were the children acquired vocabulary in English and their interest in English learning was increased. The prototype was a bilingual book with two different versions, including different parts of the dialogue in Japanese and English. This book takes a natural approach to increasing vocabulary and phrases in the child's foreign language. For future study, Hamilton suggested more instructions for parents and teachers who are not familiar with the 
foreign language should be included and the frequency of weekly reading should be more realistic. Although the small sample size of this study makes it hard to generalize the findings, this prototype shows to be a promising resource for teaching a foreign language. After more research and more development of the prototype, this bilingual book could easily be implemented into the early American education system to help children learn a foreign language at pre-school age.

These different teaching techniques and resources show the ideal educational setting and material that help children the most in becoming proficient in learning their foreign language. By implementing these techniques and utilizing these resources in the early education system, American school districts could create educational environments that help the students master a foreign language. Creating national education requirements for foreign language learning in early education, implementing these different approaches, and following the example set by other countries, the United States could foster foreign language learning in early elementary classrooms across the country.

\section{Methodology}

The purpose of my research is to investigate why the Texas education system waits until high school and higher education to teach students a foreign language despite the evidence of the benefits of teaching children a foreign language at a young age. To conduct my research, I asked various Texas educators their opinions on the topic by using a two-section questionnaire. One section of the questionnaire includes three open-ended questions about foreign language learning and the benefits while the other section includes statements about the Texas education system and foreign language learning. For the second section, the participants responded to the statements using a likert scale ranging from strongly disagree (1) to strongly agree (5). All the sections of my questionnaire were answered by 21 Texas educators ranging from elementary to high school.

The participants in my research are 21 Spanish educators in the Texas education system that include elementary school, middle school, and high school levels. The participants are from different Texas school districts, including Avinger Independent School District, Richardson Independent School District, Frisco Independent School District, and Lewisville Independent School District. I found participants through my personal contacts, contacting the head of the foreign language departments at the various school districts, and handing out an interest form in a graduate-level Spanish class at the University of North Texas that had several Spanish high school teachers. After initial contact through me or the heads of the foreign language departments and the participants agreed to participate, the questionnaire was sent to the participants via email. The email included the link to the questionnaire which was created on the online questionnaire generator Qualtrics.

A total of 30 educators responded to my questionnaire; however, only 21 of these responses were complete. Out of the 9 participants who did not complete the questionnaire, 1 participant did not finish Section 1 and the other 8 participants did not complete Sections 1 or 2. For 7 of the participants who did not finish Sections 1 or 2, the questionnaire malfunctioned and Sections 1 and 2 were not presented to the participants. The other 2 participants who did not complete the questionnaire did not completely fill out all the sections. I was not able to contact these participants and ask them to complete the questionnaire again because they did not put their name in the questionnaire. In addition to not having their names, 8 of these participants were not contacted directly by me but through the head of their foreign language department. Since these 9 participants did not fully complete the questionnaire, I did not count any of their information in the analysis of my data.

The demographic section of the questionnaire had questions for the participants to provide personal and professional information. The personal information provided was name, age range, gender, first language spoken at home, and dominant language. The professional information provided was school district, level they teach, what Spanish classes they teach, and school type, either public or private. Providing their name was optional for the participants while everything else was required. While all of the demographic information collected is important, only some of the information is particularly relevant to my research. All of the school districts the participants work at- Richardson ISD, Frisco ISD, Lewisville ISD, and Avinger ISD- are public schools. Most of the participants taught at the level of middle school or high school because there are currently not many foreign language learning programs being implemented at the elementary school level. Figure 1 is a graph that shows the distribution of the levels taught by the teachers. Out of the 21 educators who completed my questionnaire, 4 were males while the other 17 participants were females. The age range of the participants had much variation and is represented in Table 1.

\section{Distribution of Levels for the teachers}

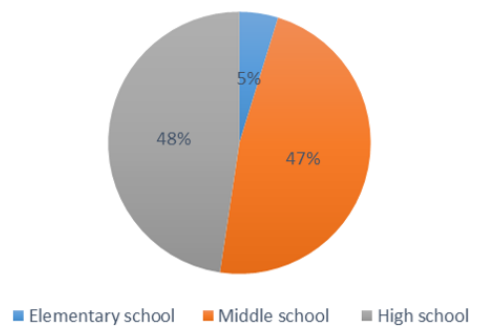

Figure 1. Distribution of Levels for the Teachers

The first section of the questionnaire gathered qualitative data of the educator's opinions in the form of open-ended responses. The questions asked on the first section of the questionnaire investigated why the educators believe the Texas education system waits until later to implement foreign language education, why funding is not being made available 
Table 1. Age Ranges of Participants

\begin{tabular}{cc}
\hline Age Ranges & Number of Participants \\
\hline $25-34$ & 6 \\
$35-44$ & 9 \\
$45-54$ & 3 \\
$55-64$ & 2 \\
$65-74$ & 1 \\
\hline
\end{tabular}

for a program that has been proven to be beneficial, and what are some perceived benefits of foreign language learning at a younger age. These questions helped me gather the educator's opinions about foreign language learning in the Texas education system and the benefits in a subjective format. The second section of the questionnaire gathered quantitative data of the educator's opinions in the form of scaled responses. The second section of the questionnaire included various statements about foreign language learning in the Texas education system, the effect of age on foreign language learning, and potential factors hindering implementation of foreign language learning early on in the Texas education system. The educators gave their opinions using a likert scale that had five options which included: strongly disagree, disagree, neither disagree or agree, agree, and strongly agree. Collecting data by using a likert scale allowed me to collect numerical data of the opinions provided by the participants. Refer to Appendix 1 to see the actual questionnaire that was used during my research.

Theory: The absence of foreign language instruction in early education in the Texas education system is due to four possible factors: funding, number of educators, available resources, or opinions against foreign language learning at a young age.

Hypotheses:

- The number of educators and resources needed for implementing a foreign language learning program in elementary education is directly correlated with the lack of funding available for this particular program.

- Educators' and parents' opinions that learning a foreign language at a young age is more harmful than beneficial to the child hinders the ability to gain support for implementation of this type of program.

\section{Results}

During my research, I collected the opinions of 21 participants in the form of qualitative data in Section 1 and in the form of quantitative data in Section 2 of the questionnaire. Refer to Appendix 1 to see the questions and statements used in the questionnaire. Section 1 includes three open response questions which allowed insight into the opinions of educators. There were general themes and patterns found in the open-ended responses. Section 2 is made up of several statements that the participants used a likert scale to express their opinions. Although most of the participants were in agreement on some statements, their opinions varied about other statements. The opinions from this section are represented in various charts and graphs.

\subsection{Open-Ended Questions}

One of the open-ended questions found in Section 1 is "Why do you believe the Texas education system waits until high school or secondary education to put emphasis on teaching a foreign language instead of teaching children at a younger age?" The responses of the educators had general themes for why the Texas education system does not typically implement foreign language learning early in the education system. A few reoccurring responses found in the opinions of the educators are lack of funding available for such a program, lack of resources, and lack of time in daily schedules of elementary schools to implement a foreign language learning program at that level. One response expresses how lack of funding and scheduling combine together to hinder implementation. That particular response is "I think it's easier with the current schedule to send kids out for recess instead of adding an extra class and it's less costly for elementary schools to put an emphasis on teaching a foreign language at a secondary level."

Another reason for waiting to implement foreign language learning in high school is that it has always been this way and there is not a push from educators and the people to change it. Some of the participants believe that foreign language learning is not valued or seen as a priority, therefore, foreign language learning is seen as less important than other core subjects such as Math, Science, Social Studies, and English. Also, foreign language learning or language other than English (LOTE) is often identified as an elective in schools. "English is perceived as the dominant language for doing business and academics. United States is territorially large, there has not been a need for endorsing speaking multiple languages," is an opinion that could possibly explain why value is not seen in foreign language learning and why there is not a push for change.

The lack of value placed on foreign language learning at a young age and lack of knowledge about the benefits of learning foreign language early were two patterns seen throughout the response of the educators. Some of the educators believe that people who make laws are not knowledgeable with foreign language education or research. One response from a participant expresses how the lawmaker's lack of knowledge affects implementation of foreign language learning programs early on. This particular response is "Because they are stingy, close minded, totally unaware of the research and spend the state tax money on business-friendly road projects, development projects and tax incentives."

There are several responses from the participants that clearly articulate their opinions on why foreign language learning is implemented later in the education system. I believe these direct quotes of the participant's responses exemplify the patterns found in the responses to the first open-ended 
question in Section 1. I have listed these responses below in quote form.

"I think it's totally an issue of resources-not enough $\$$ for foreign language teachers in elementary and not enough time in the elementary schedule"

"There is not enough time in the day. There are too many things to teach for the STAAR test. Also, if it is a low economic population, they have other issues that override foreign language instruction."

"I believe that our education system fails to see the importance of speaking more than one language and so it fails to implement it into elementary schools. The entire structure of our school system does not lend itself to easily incorporate a foreign language program into many elementary schools. Lastly, perhaps we still live in a country where the majority of the population still does not value connecting with people that are nonEnglish speakers or to understand or value other cultures."

"I believe that Texas waits until the high school level because they feel that there are too many demands on time for educational skills that are seen as far more critical and fundamental. There are many calls on classroom time available in elementary and middle school classes. I also believe that this approach is based on a national and cultural view of there being no "real" need for a second language. And, I believe that this view has grown from the fact that the boundaries of our contiguous states are only shared with Canada (predominantly English-speaking) and with Mexico. Often, many Americans will say that Mexicans need to learn to speak English when they come to the US. Finally, funding seems to be stretched to its limits (according to lawmakers and administrators); that would prevent implementation below the secondary level, except in 'richer' districts. It should be noted, however, that other states are experimenting with use of other languages to teach 'core' skills in the primary and elementary settings."

"I do believe that I have an educated understanding of why Texas waits until secondary education to begin with foreign language instruction. I think maybe there is the misconception that students will better be able to master it when they are more mature and have a better grasp of their first language. I lived and worked in an elementary school in Spain for a year where the children studied Spanish, Gallego, English and Portuguese. I think that Americans can get away with only speaking English and don't feel the need to learn other languages and therefore, don't incorporate it into the education system."

In addition, one of the participants mentioned that " $\mathrm{Be}$ cause as a society, the US has been very ethnocentric and LOTE has been historically viewed as a threat to nationalism."

Another one of the open-ended questions is "If funding is a factor preventing foreign language learning in early education, why is funding not being made available for educational requirements that have been shown to be very beneficial for young children?" Many of the responses to this question echoed the themes and patterns found in the responses of the first question. There were other patterns and themes found in the responses that were not found in the responses to the first question.

Some responses mentioned that funding depends on the school district and this is why some school districts can afford foreign language learning programs in early education while other school districts cannot afford implementation of this type of program. Some participants mention the issue of funding being cut for school districts, especially in early childhood education programs. Lack of funding may also be due to the fact that foreign language instruction is perceived as an enrichment program instead of a necessity for educational purposes. Also, in low economic school districts there may be other issues that outweigh the need for foreign language implementation in early education.

Some of the patterns found in the responses to the first open-ended question echoed in the responses to the second open-ended question are value not being seen in foreign language learning, not seeing the long-term benefit, lack of knowledge about the benefits of the program, and lack of room in elementary schedules to implement the program. If value is not seen in foreign language learning at an early age then the funding will be spent elsewhere. One participant summed this up perfectly and provided examples by stating "Perhaps for the same reason, proper exercise for our students is not valued as it should, healthy breakfasts are many times not provided. If people don't value it, no matter how much money is available, the funds will be spent elsewhere."

A few responses from the participants perfectly sum their opinions and the opinions of others about funding not being provided for foreign language learning programs at an early age. These responses point out general issues of funding and mention general confusion on why funding is not being provided. The responses are listed below in the form of quotes.

"I wonder the same, especially since it would make more sense financially to have students proficient in a LOTE by high school graduation. It would cut costs in Higher Education, where an 
average 3 credit class costs $\$ 700$ and many majors require at least 4 semesters of a LOTE for graduation, not to mention the fact that it would educate ALL citizenry, not only those pursuing post-secondary studies."

"Funding is a factor because you have to get a classroom and scheduling. Hiring bilingual teacher is not the same as hiring a foreign language teacher. I think that there is not enough data to back up the educational benefits of young bilingual children."

"Again, making funding available seems to be based on what skills are deemed as critical and necessary for teaching at levels prior to secondary. I also believe that many of the powers that plan and provide funding do not buy into the research that indicates the benefits of learning a foreign language in early childhood, primary, and/or elementary settings."

I think that the American education system is behind in so many areas that they are just trying to "catch up" on what they consider to be "core" subjects and so foreign language gets put on the back burner. We also have so many children coming from so many places that schools work so much on just teaching them English and that adding foreign language probably seems overwhelming.

The final question in Section 1 is "What do you believe are the benefits of learning a foreign language at a young age?" The participants in the questionnaire provided many examples of what they individually believe are benefits of children learning a foreign language at an early age. Almost all of the benefits provided in the responses can be divided into the following five categories of benefits: cognitive development, emotional characteristics, cultural awareness, professional opportunities, and ability to learn foreign language with ease.

The educators provided many examples of cognitive benefits gained through learning a foreign language at an early age. According to the educators, the five components of language phonology, morphology, syntax, semantics, and pragmaticsand pronunciation can be strengthened and acquired naturally if the foreign language is learned at a young age. A specific example of this process was given by a participant who expressed that learning a foreign language at a young age creates "connections not only with prefixes and suffixes but as well as cognates and a better understanding of grammar." The responses indicated that learning a foreign language, especially at a young age, develops the brain and makes beneficial changes to the brain. These changes include improving and increasing critical thinking, problem solving, intelligence, creativity, imagination, and metacognition. Learning a foreign language develops multi-processes, a wider spectrum for learning, patterning skills, comparison/contrast skills, cultural skills, social skills, and habits of focusing. Learning a foreign language at a young age while the brain is doing a lot of development, creates connections between the two hemispheres of the brain. One participant expressed that "research proves that people who speak more than one language use more of their brains and actually "unlock" parts that some people never access." This response shows the developmental changes learning a foreign language at an early age can have on the brain in terms of cognition.

Many benefits were provided for the categories of emotional characteristics, cultural awareness, and professional opportunities. Passion for learning, compassion, empathy, and curiosity are some of the emotional benefits that were mentioned. Learning a foreign language at an early age benefits someone culturally by allowing them to develop cultural understanding, tolerance, and proficiency. Having a larger population of bilinguals or multi-linguals creates more professional opportunities for individuals and for success on a broader scale.

Many of the participants expressed in the questionnaire that people have an easier time learning a foreign language if they learn it at an early age. This ease is possibly due to the fact that children are able to better absorb a second language. A few of the educators attributed this ease to the fact that children are risk takers and are less afraid to try when learning a foreign language. Some of the educations mentioned that children have a desire to learn and are more open to learn a language that possibly enriches their potential. The fact that children are more able to reproduce sounds in a foreign language and therefore have more ease in pronunciation was a benefit listed. One major benefit mentioned was that the earlier the exposure to the foreign language, the more retention.

There were many benefits of learning a foreign language at a young age provided by the participants in the third openended question in the questionnaire. I have chosen some responses that give a holistic view of the possible benefits. The responses are provided below in quote form.

"If the student's only time to learn the language is limited to the classroom then they need to start younger so they can develop more fluency, broader vocabulary and better retention"

"Exposure to the language over the long-term is the proven way to promote and for students to actually achieve language acquisition."

"Research has shown that children learn language naturally at a very young age but as we grow older the ability to learn a language is lost sometime prior to puberty. If children were taught between the ages of 2 - 9 they would learn on the same side of the brain as their first language making them bi-lingual. Once a child has lost the ability to naturally learn language the learning process for a second language is transferred to the opposite side of the brain which means that language must be taught in a totally different manner and it is much more difficult to learn." 
"While it's clear that not only is it learned at a faster rate with accent reduction (plus the many cognitive advantages) but beginning to learn a different language in those first seven years allows a child to emotionally and psychologically develop with the awareness that they can connect with others from that second language. This leads children to cement the understanding of other cultures, respecting other races, and expanding their horizons into their psyche."

"The students do not question why things are said or done (conjugation, word order, noun adjective agreement, etc.) a certain way. In my 24 years of teaching, high school students want to know why things are done or said a certain way."

\subsection{Likert Scaled Questions}

Section 2 of the questionnaire included several statements about foreign language learning that the participants responded to using a likert scale with the options of strongly disagree (1), disagree (2), neither agree or disagree (3), agree (4), and strongly agree (5). The statements were split into three subsections which are foreign language learning in the Texas education system, the effect of age on foreign language learning, and potential factors hindering implementation of foreign language learning early in the Texas education system. The responses from the second section of the questionnaire are represented in various charts and graphs.

The 'foreign language learning in the Texas education system' subsection of Section 2 of the questionnaire includes 8 different statements. The first statement is "The current way the Texas education system implements foreign language learning is effective." Table 2 and Figure 2 show that while some participants agree or are indifferent to this statement, most of the participants either disagree or strongly disagree with this statement. To make the pie chart, I combined the data for disagree and strongly disagree together into one category and the data for agree and strongly agree together as well. Table 3 and Figure 3 represent the data for the statement "The current way the Texas education system implements foreign language learning needs to be changed." These graphs show that most of the participants either agree or strongly agree with this statement. The next three statements investigated at which level the participants believe foreign language learning should be implemented in the education system. The three statements used to gather this data were "Foreign language learning should be implemented in high school, middle school, or elementary school." The data from these three statements were combined by finding which level the participants believed foreign language learning should first be implemented. If the participants had one level higher than the other two, it was interpreted as the level they believe foreign language should first be implemented. If the participants gave all three levels the same value, it was interpreted that they believed foreign language learning should first be implemented at the elementary level. Table 4 shows that almost all of the participants believe foreign language learning should first be implemented at the elementary level.

Table 2. The current way the Texas education system implements foreign language learning is effective.

\begin{tabular}{cc}
\hline Likert Options & Number of Responses \\
\hline Strongly Disagree & 6 \\
Disagree & 8 \\
Neither agree nor disagree & 5 \\
Agree & 2 \\
Strongly agree & 0 \\
\hline
\end{tabular}

Table 3. The current way the Texas education system implements foreign language learning needs to be changed.

\begin{tabular}{cc}
\hline Likert Options & Number of Responses \\
\hline Strongly Disagree & 1 \\
Disagree & 1 \\
Neither agree nor disagree & 0 \\
Agree & 11 \\
Strongly agree & 8 \\
\hline
\end{tabular}

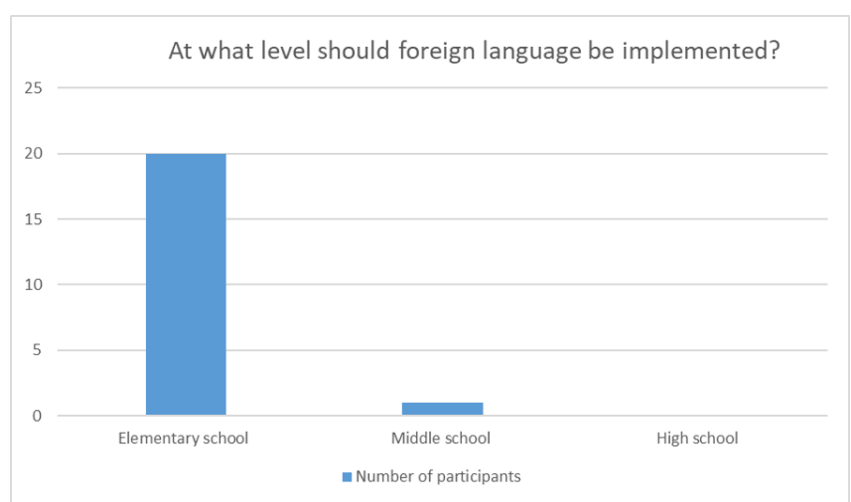

Figure 2. Level of Implementation

The next section contained statements about the effects of age on foreign language learning. The first statement in this subsection is "Children learn a foreign language easier than adult learners" and Table 4 shows that most of the participants agree or strongly agree with this statement. "The ability to become proficient in a foreign language decreases as a person ages" is the second statement of this subsection and the responses of the participants are varied. While the responses are varied, 14 participants agree or strongly agree with this statement and only 5 participants disagree or strongly disagree. Most of the participants agree or strongly agree with the statement "People who begin foreign language learning in childhood will be able to become proficient in a foreign language." For the next two statements, "People who begin foreign language learning in adolescence will not be able to become proficient in a foreign language" and "People who 
begin foreign language learning in adulthood will not be able to become proficient in a foreign language," majority of the participants were neutral or disagreed/ strongly disagreed. Table 5 illustrate that most of the participants disagree or strongly disagree that people will not become proficient in a foreign language if they begin learning during adolescence or adulthood.

Table 4. Children learn a foreign language easier than adult learners.

\begin{tabular}{cc}
\hline Likert Options & Number of Responses \\
\hline Strongly Disagree & 0 \\
Disagree & 2 \\
Neither agree nor disagree & 0 \\
Agree & 7 \\
Strongly agree & 12 \\
\hline
\end{tabular}

Table 5. Learning foreign language at too early of an age can have negative effects on the child's first language.

\begin{tabular}{cc}
\hline Likert Options & Number of Responses \\
\hline Strongly Disagree & 15 \\
Disagree & 2 \\
Neither agree nor disagree & 1 \\
Agree & 0 \\
Strongly agree & 3 \\
\hline
\end{tabular}

In the third section of the questionnaire, there are four statements inquiring about the potential factors hindering implementation of foreign language learning early in the Texas education system. The four potential factors presented by the questionnaire are funding, limited number of foreign educators, lack of resources, and opinions against foreign language learning. The responses to whether limited number of foreign educators is a limiting factor are varied. Although the responses are varied, results show that majority of the participants agree or strongly agree this is a potential factor. An equal number of participants disagree/strongly disagree and agree/strongly agree that lack of resources is a potential factor that may hinder the implementation of foreign language learning at the elementary level. Figure 3 illustrates the responses of the participants to this question. For the statement about whether opinions against foreign language learning is a hindering factor, majority of the participants agree with this statement.

\section{Limitations}

While the research was effective at collecting the opinions of several Texas educators about the current state of foreign language learning in the education system, there were a few limitations in the study. Although the limitations were not a major hindrance to the research, the data would have been more complete and conclusive without the effect of the limitations. The main limitations of the research study were
Table 6. Opposition to foreign language learning is a potential factor.

\begin{tabular}{cc}
\hline Likert Options & Number of Responses \\
\hline Strongly Disagree & 3 \\
Disagree & 1 \\
Neither agree nor disagree & 3 \\
Agree & 6 \\
Strongly agree & 6 \\
\hline
\end{tabular}

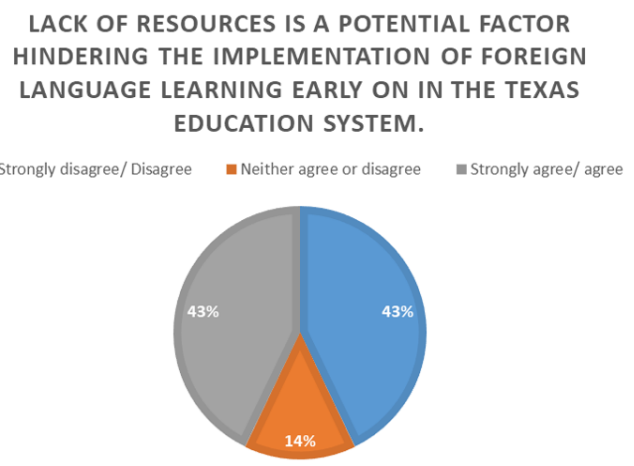

Figure 3. Potential Factor of Lack of Resources

ambiguous wording of some statements in the questionnaire, method of contact with some of the participants, the small sample size, and the time available to conduct research.

Some of the statements in the questionnaire were unclearly worded and might have affected how the participants responded to the particular statements. The effect of the ambiguously worded statements was evident in the responses of some of the participants because their answers were not in accordance with what I expected. One set of unclearly worded statements is a set of three in Section 2 that is gathering opinions about which level foreign language learning should be implemented. The statements for this set were worded as "Foreign language learning should be implemented in high school, middle school, or elementary school." I intended for these statements to be interpreted as which level foreign language learning should be implemented first. Although some of the participants did interpret these statements the way I intended, others interpreted it as foreign language learning should be implemented at all three levels. To make these statements clearer and receive the desired results, the statements should have been worded as "Foreign language learning should first be implemented in high school, middle school, or elementary school." Another way to make this statement clearer is to have a question with answer choices instead of three statements. The question could have been "At which level should foreign language learning first be implemented?" and have elementary school, middle school, and high school as the three options. By having clearer statements or a question instead of statements, the opinions of the educators would have provided more conclusive results.

The method of indirectly contacting some of the partici- 
pants was a limitation in my research. While I directly contacted some of the participants, other participants were contacted indirectly by the head of the foreign language departments. Because I did not have their email addresses, I was not able to contact them if there were issues with the questionnaire and if their responses were not complete. I also made filling out their name on the questionnaire optional to ensure confidentially. Since I did not have the names of some of the participants, I did not know who to contact about the issues experienced with the questionnaire. The limitation of indirectly contacting some of the participants resulted in 9 incomplete questionnaires.

The small sample size and the time available to conduct research were limitations that affected having conclusive results. The number of participants who completed the questionnaire is 21 . The opinions of 21 educators only gives a small glimpse into topic of foreign language learning in the Texas education system. A larger sample size would give a more complete and holistic view into the opinions of educators on this topic. The amount of time that was available to conduct research limited how many school districts and participants I was able to contact and also hindered my ability resend the questionnaire to those who had errors, if possible. These two limitations affected gathering a holistic view of the educator's opinions.

\section{Directions for Future Research}

I began conducting my research solely on a small group of Texas educators. To further my research, I would like to conduct research on a larger sample of Texas educators to get a more conclusive view of the opinions about the current state of foreign language learning in Texas. Also, if I had the time and resources I would like to interview educators from all 50 states in order to get a holistic view of the nation's opinion on teaching foreign language at a young age. To make the research more complete, I would like to view the foreign language requirements for each state, if I had time and access. I would like to investigate the current requirements in order to see what changes could be made in the future. Continuation of my research would allow me to collect a conclusive picture of foreign language learning in Texas and the nation in whole.

If I were to continue my research, I would also make changes to the limitations that affected my research. I would rephrase the statements to make them clearer for the participants so there would not be any confusion. Moving forward, I would make sure to contact the participants directly so I could contact them if necessary. When continuing my research, I would like to have a larger sample size and more time to conduct my research. By changing these limitations, my research would most likely be more complete.

\section{Discussion}

The results and responses provided by the participants in the questionnaire revealed many ideas about foreign language learning in the Texas education system specifically and about foreign language learning in general. The educator's opinions provided in the first section provide support for their responses to the statements in the second section. The information given in Sections 1 and 2 can be analyzed together to provide a holistic view of the opinions of the 21 educators who participated in the questionnaire.

Most of the participants do not believe the current structure of foreign language learning in the Texas education system is effective and believe it should be changed. Although the educators seem to be aware of the need for change in the current structure of foreign language learning, they are also aware of the potential factors that are hindering the implementation of foreign language learning early in the Texas education system. While being aware that the need for change is a necessary step for introducing change into foreign language learning, change cannot be introduced when there are many factors prohibiting implementation.

Many of the participants agree that foreign language learning should be implemented at the elementary level because of many benefits. The educators agree that waiting to implement foreign language learning until high school is not the most effective way to teach a foreign language and limits the full effect of the benefits a child can gain through learning a foreign language. The participants agree that there are many cognitive, emotional, cultural, and professional benefits of learning a foreign language at an early age. The educator's responses can be interpreted as they believe the benefits of this type of program outweigh the prohibiting factors.

Even though the implementation of foreign language learning state wide is not in the near future, the educators have some ideas about what this type of program would look like. They believe that an immersion setting is better than a formal instruction setting for the children to learn a foreign language. While the type of immersion program they have in mind most likely does not include travel and full immersion in the foreign language, it could possibly include teaching some of the student's classes in the foreign language. By immersing the children in the foreign language instead of limiting their interaction with the language to just listening to instruction about the language, they get to experience the language and have practice using the language in practical ways.

Although many of the participants agree about the benefits and what this program would look like, they also agree the daily schedule in elementary schools currently does not allow for the implementation of this type of program. The educators expressed their opinions that the current elementary schedules are filled with core classes such as Math, Science, English, etc. and allow no room for implementation electives such as foreign language learning. The lack of room in schedules for foreign language learning could be due to the fact that core subjects are valued more than foreign language learning. The lack of available room in elementary schedules for the implementation of foreign language learning programs could be due to the fact there is little value placed on foreign language learning. 
While the educators believe that children have an easier time learning a foreign language than adults, they do not deny the fact that adolescents and adults still have the ability to learn and become proficient in a foreign language. This opinion could be due to the fact that some of the educators learned foreign language during adulthood and know from personal experience that it is possible to become proficient in a foreign language as an adult. It is possible that this pattern was found in the responses because proficiency could have various meanings for different people. While some people may believe proficient to mean native-like fluency, others may define proficiency as being able to master one area- oral, listening, comprehension, writing, and reading. Although becoming proficient is possible during adulthood, the educators do see the benefit and ease of teaching children a foreign language at a young age. Most of the educators believe that learning a foreign language at too early of an age does not have negative effects on the child's first language. Actually, some of the responses in the open-ended sections show that the participants believe the earlier a foreign language is taught the more beneficial it will be for the child.

While the educators are in agreement that there are factors hindering the implementation of foreign language learning in early education, there are some differences of opinions on what these limiting factors are. Most of the participants believe funding is a hindering factor because the people in charge do not see the value in foreign language learning at an early age, therefore, the funding is directed elsewhere. Limited funding for foreign language learning programs also limits the number of foreign language educators that can be hired and properly trained and also limits the amount of resources available for early education foreign language learning programs. A large portion of the participants believe that opinions against foreign language learning hinder the implementation of a foreign language learning programs early on in education. These negative opinions could possibly be people not seeing the value in foreign language learning, believing foreign language learning is not necessary, and believing English is the only language needed in America. Although the educators have differing opinions about the specific factors limiting the implementation of foreign language learning at the elementary level, they do agree there are factors prohibiting the implementation of beneficial program that could help children easily become proficient in a language.

\section{Conclusion}

The research provided multiple answers to my research question, "why does the Texas education system wait until high school and higher education to put emphasis on learning a foreign language, even though it has been shown that humans have the most capacity to learn language at a young age?" in the form of responses from Texas educators. According to the opinions provided in my research, foreign language learning is not implemented in early education, specifically in Texas, because of funding, limited number of educators, lack of resources, and opinions against foreign language learning at a young age. Some of these factors that limit the implementation of foreign language learning at the elementary level are due to the fact that people do not see the value in this type of program and do not make foreign language learning a priority. If a program is not prioritized and not deemed as valuable, despite research, funding will go elsewhere. Reviewing the literature also revealed a path for moving forward in changing the absence of foreign language learning in early education by demonstrating a need for national foreign language requirements in the American education system and providing different ways to potentially implement foreign language learning in early education. Although the opinions of the 21 Texas educators who participated in my research provided answers for my research question, further research should be conducted on a larger sample size to get conclusive and holistic results before implementing change into the Texas education system and the American education system as a whole in the future. While I have not reached a conclusion on how to implement changes into the Texas education system and later the American education system, I have the ground work for moving forward and hopefully making a much needed change in early education in the American education system.

\section{Author Biography}

Krystin White is from Atlanta, Texas. She graduated with honors in May 2017, with a Speech-Language Pathology major and a minor in Spanish. Krystin has been a part of the Honors College since her freshman year at UNT. She is currently pursuing a Master's in Speech-Language Pathology at UNT to become a clinical Speech-Language Pathologist. She plans to continue research in the area of language with potential focus on aphasia.

\section{References}

[1] Stephen D Krashen, Michael A Long, and Robin C Scarcella. Age, rate and eventual attainment in second language acquisition. TESOL quarterly, pages 573-582, 1979.

[2] Vanessa Cardinale. America's need for a foreign language requirement. The Review: A Journal of Undergraduate Student Research, 6(1):12-16, 2003.

[3] Kat Devlin. Learning a foreign language a 'must' in europe, not so in america. Pew Research Center, 2015.

[4] Mehri Farzaneh and Mostafa Movahed. Disadvantage to pre-school children learning a foreign language. Theory and Practice in Language Studies, 5(4):858, 2015.

[5] Bonnie Billak. Second language acquisition at the early childhood level: A 5-year longitudinal case study of prekindergarten through first-grade students. TESOL Journal, 4(4):674-696, 2013.

[6] Kirstin Bergström, Maria Klatte, Claudia Steinbrink, and Thomas Lachmann. First and second language acquisition 
in german children attending a kindergarten immersion program: A combined longitudinal and cross-sectional study. Language Learning, 66(2):386-418, 2016.

[7] KP Shine. Differences between second language learning and first language acquisition. Language In India, 11(11):736-744, 2011.

[8] Terry Kit-fong Au, Leah M Knightly, Sun-Ah Jun, and Janet S Oh. Overhearing a language during childhood. Psychological science, 13(3):238-243, 2002.

[9] Robert Hamilton. Bedtime stories in english: Fieldtesting comprehensible input materials for natural secondlanguage acquisition in japanese pre-school children. Journal of International Education Research, 10(3):249, 2014. 